\title{
Role of Foreign Language Teacher Shaping Students' Research Skills
}

\author{
Olga Vladimirovna Lopatina ${ }^{1}$, Anatoly Mikhailovich Borisov ${ }^{2}$, Irina Ilyinichna Leyfa ${ }^{3}$, Ilkhamiya Iskhakovna \\ Galimzyanova $^{4}$, Lyubov Pavlovna Yatsevich ${ }^{3}$, Marina Alexandrovna Demyanenko ${ }^{3}$ \& Alfiya Rafisovna \\ Masalimova $^{2}$ \\ ${ }^{1}$ Kazan National Research Technical University named after A. N. Tupolev, Tatarstan, Kazan, Russian \\ Federation \\ ${ }^{2}$ Kazan Federal University, Kazan, Kremlyovskaya, Russian Federation \\ ${ }^{3}$ Amur State University, Blagoveschensk, Russian Federation \\ ${ }^{4}$ Kazan State Conservatoire (Academy) named after N. Zhiganov, Kazan, Russian Federation \\ Correspondence: Olga Vladimirovna Lopatina, Kazan National Research Technical University named after \\ A.N. Tupolev, Tatarstan, 420111, Kazan, K. Marks Street, 10, Russian Federation. E-mail: alfkazan@mail.ru
}

Received: September 27, 2014 Accepted: December 27, 2014 Online Published: January 14, 2015

doi:10.5539/ass.v11n4p135 URL: http://dx.doi.org/10.5539/ass.v11n4p135

\begin{abstract}
Nowadays many foreign language teachers are not enough aware about the significance of the research component within their profile discipline, arguing that students even in their native language do not have enough use of fundamentals in their scientific professional activities. Therefore, this article is aimed to study the role of foreign language teacher when mastering students' research skills in the process of learning English as a foreign language. The study results have confirmed that process of mastering students' research skills when learning foreign language is directly connected with their teacher's own research skill level. These article materials have practical value both for foreign language teachers and for students enrolled for foreign languages programs of education sciences faculties at high schools.
\end{abstract}

Keywords: teachers, qualification courses, research skills, "foreign language" discipline, students

\section{Introduction}

Without defining the role of foreign language teacher who arranges cognitive activities and student's personal development process, successful creative and intellectual development of future professional cannot take place. V. T. Aschenkov has authenticated that teacher's high status stability can be guaranteed only when he appears as a research scientist himself (Aschenkov, 1989). From N. V. Kuzmina's and A. A. Rean's viewpoint, the very learning process at high schools should be the subject for scientific research, and the research approach to students' training and educating should be the driving style of teaching activities at universities (Kuzmina \& Rean, 1993).

Teachers do not always realize the significance of acquiring students' research skills when learning foreign languages, justifying their position by tough time limits for "Foreign Language" discipline, and this fact leaves no room for acquired knowledge analysis (Lopatina, 2009.). Natural process of logical perception is being excluded from study process, even if it is here to contribute to research skills mastering. At the same time, the fact that reflection plays a decisive role in language skills development is being disregarded. In addition, multiple thoughtless repetition is not efficient at developing a creative thinking (Shaidullina \& Ivanenko, 2012).

\section{Materials and Methods}

In order to conduct this study the following methods have been used: research and generalization of innovative teaching practices; in-depth analysis of foreign language departments experience at universities; analysis of local and foreign educational programs including textbooks and manuals in terms of their subject and content; psycho-pedagogical, sociological data collection methods (teacher's survey, questionnaires and interviews, teaching experience analysis as well as students and teachers performance results analysis); statistical analysis and research results interpretation and their mathematical processing and some others.

Two students and teachers groups at Kazan Federal University and Kazan National Research Technical University named after A. N. Tupolev took part in this empirical experimental work. 
46 teachers at Kazan Federal University and 32 teachers at Kazan National Research Technical University named after A. N. Tupolev took part in training programs improving their qualifications.

Research had been conducted in 3 stages:

First stage (preparatory)-resulting material had been generalized, essential characteristics of person's research competence had been identified; choice of science-based searching methods had been determined; research methods program had been elaborated.

Second stage (main)-modern requirements for foreign language teaching content had been uncovered; both local and foreign teaching methods of foreign language had been included in the research, since its them to ensure integrity and regularity of mastering students' research skills in economics program; reasons behind low level of mastering students' research skills had been identified; scientific and methodological support for foreign language teachers in order to shape students research skills in process of language study had been elaborated.

Third stage (final)-systematization, generalization and pedagogical interpretation of study's empirical results had been carried out; experimental verification of scientific and methodological support for foreign language teachers in order to shape students' research skills during learning process had been conducted as well.

\section{Results}

We have developed and introduced a special course "Students' research skills: its features in process of foreign language study" for teachers of discipline "Foreign Language". This course contributes to the choice of optimal content of foreign language teaching methods, aimed at creating students' research skills.

In order to research teachers' viewpoints about an issue of training and methodological support usage during educational process at high schools we have conducted certain interviews. As a result of this study we have revealed that in process of updating foreign language teaching content in modern conditions it is crucial to focus on several aspects:

1) trainee should be in the center of learning process regarding his needs and interests; 2) other students should be regarded as a collaboration group where dialogues, mutual aid, and self-assessment take place; 3)teacher should act as coordinator and assistant to trainee when needed;4) it is crucial to increase student's motivation to study foreign language by introducing interesting and useful information which can be implemented in his future professional activity; 5) There should be a vivid skills improvement of students' independent work (using books, reference literature, dictionaries, online sources, etc.) 6) foreign language learning content is a good base to shape research skills (Lopatina \& Ratner, 2011).

On final experiment stage, we analyzed certain factors affecting research skills development level. To make it more effective we split study groups into four subgroups:

1) Groups where teachers have scientific degrees, conduct scientific studies or participate in scientific research grants; they are totally aware of this activity importance;

2) groups where teachers have scientific degrees, but they are engaged in research activities according to their Department's research plan;

3) groups where teachers have scientific degrees and teachers who are engaged in their PhDs preparation;

4) groups, where teachers do not have scientific degrees and they are not involved in any research activity.

The level of research skills development had been measured and analyzed while experiment in such groups.

Table 1. Levels of students' research skills formation depending on their teachers' activity types

\begin{tabular}{lllll}
\hline $\begin{array}{l}\text { Groups } \\
\text { Levels }\end{array}$ & 1 & 2 & 3 & 4 \\
\hline passive -reproductive & 24 & 42 & 45 & 54 \\
in active search & 36 & 22 & 25 & 27 \\
intensive-creational & 38 & 35 & 28 & 18 \\
analytical-introspective & 2 & 1 & 2 & 1 \\
\hline
\end{tabular}

Single factor dispersion analysis showed that at significance level $\alpha=0,05$ research skills development level of teachers affects students' research skills development level as well. In groups where teachers are involved in 
research activities, level of research skills development of students is significantly higher.

Nevertheless, during experimental work preparation we have revealed low interest level from teachers' side not only towards their own research activity but also towards students' research activities. We have elaborated the questionnaire that allowed us to determine motivation level as well as cognitive and activity-based components within educational research process.

Questionnaire result prior the specific course has shown that teachers are quite familiar with students' research activity types, but are little aware about teachers research activities. The research activities importance was mainly pointed out for university development ( 8.5 points in average), then for students ( 7.8 points), but the importance of this activity for teachers was the modest-only 5.1 points, although respondents' majority did not consider the payment a compulsory factor $(79 \%)$.

Research activities where teachers are involved are following:

a) I am writing monograph on certain problematic topic-11\%;

b) I am engaged in teaching effectiveness increase process (as a research topic)-34\%;

c) I have an order on a certain research topic- $21 \%$;

g) I take part in a research within a grant program-32\%;

Teachers noted that the most motivated for research activities are first and fourth year students, but there are only $15 \%$ teachers involved in this activities, the others believe that the initiative for research should come from student himself or university management, but not from them.

46 teachers at Kazan Federal University and 32 teachers at Kazan National Research Technological University named after A. N. Tupolev had graduated this training courses within this program. In order to record survey results we had interviewed teachers at start and finish of the course.

To develop students' research, creative and cognitive activity the teacher also has to look for various ways to create a special educational atmosphere that encourages creativity. Modern high school teacher should use not reproductive teaching methods in his professional activity, but vice versa, productive methods aimed at developing student's creative potential. These include the following: learning technology through cooperation, aimed at socialization and communicative skills formation in students' mutual active study process while learning a foreign language; project method, meaning work with a variety of information sources in a foreign language in order to improve certain aspects of speech etiquette and research skills development; method of situational analysis, aimed at learning practical skills to work with information in a foreign language: extraction, structuring and ranking problems on importance basis and students' communicative competence development; learning technology for spontaneous speech, allowing students to acquire skills of oral speech in a foreign language within relatively short time period and due to creative exercises application; Internet technologies help to intensify learning process, motivate students' cognitive activity through participation in testing, quizzes, competitions, contests, onlineconferences and others.

Thus, our experiment on implementation of scientific and methodological support in order to prepare and train teachers of "Foreign Language" discipline, lets the teacher to choose optimal content and teaching methods of foreign language, to create students' research skills within economic educational programs.

\section{Discussions}

The necessary knowledge on this topic is provided in modern psychological and pedagogical literature that may be a prerequisite to solve the existing problem: the problem of forming students' readiness for research activities is discussed by I. J. Lerner (1994), R. A. Nizamov (1975), Y. A. Ponomarev (1990), N. Y. Postalyuk (1997), F. L. Ratner (1997), A. I. Savenkov (2006), A. V. Tretyakova (2002), T. I. Shamova (1994) etc.; the issues of students' teaching and research are presented as well by A. I. Mamot (2002) and others; organizational conditions of students' scientific activities are well defined, effective mechanisms for scientific creativity process development in constant professional education are descripted by V. V. Afanasyev (2001), T. I. Babaeva (2003), V. I. Belozertsev (1998). The role of technologies in students' research skills shaping is revealed by M. N. Berulava (1998), V. P. Bespalko (1995); adaptive educational potential of foreign experience in students' scientific work organization is presented by A. I. Galagan (1995), A. N. Dzhurinsky (2002), G. D. Dmitriev (2000), Z. A. Malkova (1992) etc.; status of foreign language in higher education is identified by I. L. Bim (2007), A. A. Mirolyubov (2002). 
Table 2. Teachers interview results before and after the course

\begin{tabular}{lll}
\hline & До & После \\
\hline 1) Rate on a 10 points-scale the importance of research for: & & 8,9 \\
a) teacher & 7,8 & 8 \\
6) student & 8,5 & 8,6 \\
в) university development & $34 \%$ & $28 \%$ \\
2)Do you consider payment for research as compulsory (yes) & & \\
3) what research activities you are involved in: & $11 \%$ & $10 \%$ \\
a) I write monograph & $34 \%$ & $76 \%$ \\
6) I am involved in education effectiveness increase & $21 \%$ & $20 \%$ \\
в) I am outsourced for research & $32 \%$ & $39 \%$ \\
г) I am involved in grant programs & & \\
4) If you are involved in a research activity: & $14 \%$ & $34 \%:$ \\
a) does it bring to you moral satisfaction & $45 \%$ & $56 \%$ \\
6) consider it as extra earning & $46 \%$ & $65 \%$ \\
в) consider it as a professional progress & $64 \%$ & $45 \%$ \\
г) consider it wasting your time since it is your Department's wish & & \\
5) do you think that at your university should be initiated certain research activities? & $15 \%$ & $78 \%$ \\
yes, this is the thing to teach & $39 \%$ & $12 \%$ \\
no, the initiative should come from student & $45 \%$ & $85 \%$ \\
6) Do you get prepared to each lesson within your discipline? & & \\
7) what conferences your student take part in? & $10 \%$ & $35 \%$ \\
1. student regional & $5 \%$ & $24 \%$ \\
2. student international & $5 \%$ & $25 \%$ \\
3. international conferences & & \\
8) What conferences language your students take part in? & $100 \%$ & $100 \%$ \\
1. Russian (Tatar) & $5 \%$ \\
2. Foreign & $15 \%$ \\
9) What amount of students participate annually in conferences and forums? & $46 \%$ \\
10) Is it possible to learn to research (yes)? & $100 \%$ \\
11) Do you reach student to research? & $15 \%$ & $65 \%$ \\
\hline & &
\end{tabular}

Various issues of students' foreign language training have been examined in PhD materials. Particularly, such as professionally-oriented foreign language learning in a not language-oriented programs high school (Alekseeva, 2002; Kuznetsova, 2002; Lesokhina, 1995; Mertsalova, 2000; Kharisova, 2001); formation of core skills, communicative culture, tolerant students' personality in foreign language learning process (Bukina, 2005; Vasilieva, 2008; Mitryuhina, 2005, etc.) integrative courses development of foreign language teaching (Meshkov, 1998; Milovanova, 1998; Filippovskaya, 2000, etc.); foreign language training for students at economic programs (Grigorieva, 2008; Mikhalkina, 1994); foreign (Megalova, 2000; Radionova, 2006; Ratner, 1997; Shaikhullin, 2006) and local experience of students' research activities organization (Ishmuradova, 2008; Karimova, 2009; Kurganov, 2008).

Nevertheless the analysis of scientific and pedagogical literature about the topic under study and our practical experience suggest that there is an the absence of scientific training support and of foreign language teachers professional development aimed to form students' research skills within this particular discipline.

\section{Conclusion}

The study results have confirmed that process of mastering students' research skills when learning foreign language is directly connected with their teacher's own research skill level. In this connection, the authors have developed and tested a special course "students research skills and their formation during foreign language learning process " for the teachers of "Foreign Language" discipline contributing to the choice of optimal content and study methods. All this is aimed at creating a students' research competence. The need to develop this special course was caused by the fact that many foreign language teachers are not enough aware about the 
significance of the research component within their profile discipline, arguing that students even in their native language do not have enough use of fundamentals in their scientific professional activities.

\section{Recommendations}

Based on problem's survey results about students' research skills formation and their development in secondary and high schools it is promising to research it in other studies as well. It is up to date not only at foreign language studies, but within other study disciplines as well, it can be also useful at forming foreign language teachers' methodological culture.

\section{References}

Afanasyev, V. G. (2001). Design of educational technology. Higher education in Russia, 4, 147-150.

Alekseeva, L. E. (2002). Optimization of the process of learning foreign language professionally-oriented dialogue of students of the Faculty of International Relations, 22.

Aschenkov, V.T. (1989). Professional adaptation of high school teachers. Armavir.

Babaeva, T. E., \& Smirnova, S. A. (2003). The role of a group of children in the education and development of children. Moscow, Academy.

Belozertsev, V. I. (1998). Professional ethics, Herald, 3, 18-23.

Berulava, M. N. (1998). Integration of educational content. Theoretical foundations of the integration of education (p. 173). Moscow: "Perfection".

Bespal'ko, V. P. (1995). Pedagogy and advanced technologies (p. 336). Moscow: Pedagogy.

Bim, I. L. (2007). Profile foreign language teaching in upper secondary school: Problems and Prospects (p. 168). Moscow Education.

Bukina, T. V. (2005). Foreign language culture graduate ssuz technological profile as a factor in its competitiveness (p. 161). Kazan.

Dmitriev, G. D. (2000). Multiculturalism as a didactic principle. Pedagogy, 10, 12-15.

Dzhurinsky, A. N. (2002). Internationalization of Higher Education. Trends and Challenges. Bulletin of Higher Education, 9, 44-49.

Filippovskaya, T. V. (2000). Formation of economic culture of pupils in the teaching of humanitarian and socio-economic disciplines. Ekaterinburg, 22.

Galagan, A. I. (1995). Methodological foundations of a comparative analysis of education. Problems of foreign higher education (p. 52). Moscow.

Grigorieva, E. V. (2008). Design and implementation of the content of learning a foreign language in high school with the internationalization of education (p. 196). Kazan.

Ishmuradova, A. M. (2008). Formation of foreign language competence of students of technical high school in independent learning activities (p. 23). Kazan.

Karimova, L. A. (2009). Content and technologies of teaching foreign languages in the modernization of higher vocational school (p. 234). Kazan.

Kharisova, G. G. (2001). Language teaching business communication language high schools students in the regional context (p. 22). Tomsk State Pedagogical University.

Kurganov, A. V. (2008). Formation of readiness of students to a liberal arts college psychological and educational research (p. 21). Kazan.

Kuzmina, N. V., \& Rean, A. A. (1993). Professionalism of teaching activities (p. 124). Saint Petersburg.

Kuznetsova, A. P. (2002). The implementation of national-regional component of the maintenance training in an integrated course on a project basis (p. 16). Moscow: Moscow. ped. State. University Press.

Lebedeva, G. A., Petrova, T. E., \& Senashenko, V. (2013). Monitoring of the educational process at the university. Print basics with students (pp. 243-266). Moscow: Alpha-Moscow.

Lerner, I. J. (1994). Modern didactics theory-practice (p. 288). Rus. Acad. Education.

Lesokhina, T. B. (1995). Features of teaching foreign scientific and technical communication at the university (p. 26). Moscow.

Lopatina, O. V. (2009). Foreign technology foreign language teaching students language high schools. Kazan Pedagogical Journal, 7-8, 163-170.

Lopatina, O. V., \& Ratner, F. L. (2011). Component composition and criteria of formation of the research 
competence of students in the process of learning a foreign language. Education and self-development, 1, 83-90.

Malkova, Z. A. (1992). Development of pedagogy at the present stage. Pedagogical theory: Ideas and problems (pp. 4-20). Moscow.

Mammoth, A. I. (2001). Organizational and methodological foundations of the operationalization of NIRS. Analyzes on the main directions of development of higher education, (5), 1-88.

Megalova, I. A. (2000). The latest information and communication technologies in the formation of foreign language competence of Russian and foreign universities (p. 180). Saratov.

Mertsalova, S. L. (2000). The technique of teaching reading authentic texts. Technology products catering (p. 47). Moscow.

Meshkov, E. V. (1998). Integrative design of the content of general education and special subjects in the conditions of the relationship of activity and secondary vocational schools (p. 219). Smolensk.

Mikhalkina, I. V. (1994). Communicative and linguistic content of teaching professional communication specialists in the field of international relations (p. 21). Moscow.

Milovanova, L. A. (1998). Formation of economic concepts in senior when learning a foreign language (p. 223). Volgograd.

Mirolubov, A. A. (2002). History of Soviet methods of teaching foreign languages. Moscow.

Mitryuhina, M. S. (2005). Continuity of formation of communicative culture in the teaching of a foreign language (p. 18). Kazan.

Nizamov, R. A. (1975). Didactic principles of activation learning activities of students (p. 302). Kazan: Kazakh State University.

Ponomarev, Y. A., Semenov, A. I., \& Stepanov, S. Y. (1990). The psychology of creativity: The total, differential, applied. Moscow science.

Postalyuk, N. Y. (1997). Basic concepts and logic design of regional educational systems. Proceedings of the Regional Scientific and Practical Conference (p. 224). Moscow Press Service.

Radionova, S. A. (2006). The content and organization technology research student teachers EU countries (p. 22). Yoshkar-Ola.

Ratner, F. L. (1997). Didactic concepts and current trends in the development of creative abilities of students in scientific activities abroad. Kazan.

Ratner, F. L. (1997). Didactic concepts and current trends in the development of creative abilities of students in scientific activities abroad (p. 27). Kazan.

Savenkov, A. I. (2006). Psychological foundations of the research approach to learning (p. 480). Publ: Axis.

Shaidullina, A. R., \& Ivanenko, N. A. (2012). Mechanisms for the preparation and selection of future competitive technical specialists. Professional education in Russia and abroad, 3(7).

Shaikhullin, T. A. (2006). Implementation of problem-based learning technology in higher education (p. 19). Kazan.

Shamova, T. I., Tretyakov, P. I., \& Kapustin, N. P. (2002). Management of educational systems: Studies allowance for stud. Higher. Textbook. Institutions (p. 320). Moscow: VLADOS.

Tretyakova, A. V. (1994). Organization of independent work of students, taking into account personal factors. St. Petersburg.

Vasilieva, A. A. (2008). Foreign language as a means of formation of intercultural tolerance among students of the university (pp. 134-140). Questions of Modern Philology and methods of language teaching in the university and the school: A collection of articles XI International Scientific and Practical Conference. Penza: RIO PGSKHA.

\section{Copyrights}

Copyright for this article is retained by the author(s), with first publication rights granted to the journal.

This is an open-access article distributed under the terms and conditions of the Creative Commons Attribution license (http://creativecommons.org/licenses/by/3.0/). 